\title{
Effects of HIF-1a overexpression on mitochondrial function in aged mice with myocardial ischemia-reperfusion
}

\author{
Tiantian ZOU ${ }^{1}$, Jianjiang WU ${ }^{1}$, Long YANG ${ }^{1}$, Tailaiti TAIWANGU ${ }^{1}$, Siyu $\mathrm{CHEN}^{1}$, Jiang $\mathrm{WANG}^{1^{*}}$
}

\begin{abstract}
To evaluate the effects of HIF- $1 \alpha$ overexpression on mitochondrial function in aged mice with myocardial ischemia-reperfusion (I/R). Mice were divided into 1) Blank (Sham) group; 2) Ischemia-reperfusion (I/R) group; 3) I/R+2ME2 group (I/R+HIF-1 $\alpha$ blocker 2ME2. Compared with Sham group, in I/R group and I/R+2ME2 group, HR slowed down, LVDP and $+\mathrm{dp} / \mathrm{dtmax}$ decreased, LVEDP, myocardial infarction area, and ROS generation rate was significantly increased; whereas the mitochondrial respiratory function (State3, RCR) and mitochondrial respiratory enzyme activity (NADH-OX, Cytc-OX and SUC-OX) were significantly reduced. Compared with the I/R group, the respiratory function of myocardial mtochondria (State3, RCR) and respiratory enzyme activity of myocardial (NADH-OX, Cytc-OX and SUC-OX) were significantly reduced in the I/R+2ME2 group; and the levels of p-HIF- $1 \alpha$ and p-VEGF in the I/R+2ME2 group were significantly decreased. HIF-1 $\alpha$ pathway upregulate the respiratory enzyme activity of myocardial and respiratory function of I/R myocardial mitochondria.
\end{abstract}

Keywords: hypoxia inducible factor-1a; myocardial ischemia-reperfusion injury; aged myocardium; mitochondrial respiratory function.

Practical Application: HIF-1 a pathway upregulates respiratory function of I/R myocardial mitochondria, providing the possible approaches for prevention of I/R injury.

\section{Introduction}

As our country's population's aging process continues to accelerate, the prevalence of acute myocardial infarction (AMI) in the elderly is getting higher and higher. The age factor is a strong predictor of the adverse outcome of AMI. About $60 \%$ of AMI deaths occur in patients over 75 years of age (Gupta et al., 2011). During AMI, myocardial cells can feel hypoxia signal stimulation, thereby activating the hypoxia signaling pathway, starting the gene expression downstream of the signaling pathway, regulating the adaptability of the cell in the hypoxia microenvironment, and maintaining the stability of the internal environment of the cell. In this process, hypoxic signals stimulate cells to induce and activate the expression of HIF-1. Studies have shown that HIF- $1 \alpha$, the active subunit of HIF-1, can rapidly activate the expression of related target genes downstream of the signaling pathway under hypoxic conditions, and promote the balance of energy metabolism by regulating the oxygen utilization in the cell (Jain et al., 2018; Williams et al., 2019) . HIF-1a has a molecular switch function in the signaling pathway. It activates the expression of HIF-1 $\alpha$ in cells under hypoxic-ischemic stress, precisely regulates downstream genes, and maintains basic cell energy metabolism (Tekin et al., 2010; Zhu et al., 2008). The results of the study confirm that ischemia postconditioning (IPostC) can activate the HIF-1 $\alpha$ pathway, significantly reduce the inifarct size of healthy young myocardium (Zhao \& VintenJohansen, 2006), reduce oxidative stress (Andersen et al., 2012), reduce the calcium ion concentration in mitochondria, and resist apoptosis (Zhang et al., 2013), effectively reduce myocardial ischemia-reperfusion injury, and provide new clinical ideas for reducing AMI reperfusion injury. However, elderly patients are the main population of AMI, and the elderly myocardium is highly sensitive to ischemia-reperfusion damage. Aging is accompanied by a decrease in the activity of the HIF-1 pathway, which is manifested as a decrease in mitochondrial function, a reduction of the number of mitochondria, and abnormal morphology (Ong et al., 2014; Bratic \& Larsson, 2013). Under aging conditions, the energy metabolism disorder regulated by the mitochondrial AMPK channel leads to a decrease in ATP synthesis's efficiency and abnormal regulation of the mitochondrial mPTP channel (Cruz-Ramírez et al., 2021; Coswosck et al., 2021; Yan et al., 2020). Therefore, this study intends to use the myocardial I/R model of aged mice to evaluate the recombinant adeno-associated virus serotype 9 mediated HIF- 1 a transfection into aged myocardium on mitochondrial respiratory function and enzyme activity, providing a basis for further research on the protective effect of aged ischemic myocardium.

\section{Materials and methods}

\subsection{Reagents and instruments}

HIF-1 $\alpha$ antibody (Abcam plc, USA); VEGF antibody (Abcam plc, USA); Horseradish Peroxidase (HRP, Abcam plc, USA); Tris Buffered saline Tween (TBST, MilliporeSigma Co., Ltd., Burlington, USA); 2-Methoxyestradiol (2ME2, Selleck 
Chemicals LLC, USA); Bradford Protein Assay Kit (Beyotime Biotechnology Co., Ltd., Shanghai, China); 2,3,5-Triphenyl tetrazolium chloride (TTN, MilliporeSigma Co., Ltd., Burlington, USA); SDS-polyacrylamide gel electrophoresis(SDS-PAGE, Weikebio Co., Ltd., Tianjing, China); ECL Western Blotting Substrate Kit (Weikebio Co., Ltd., Tianjing, China); Reactive Oxygen Species (ROS) Assay Kit (Beyotime Biotechnology Co., Ltd., Shanghai, China); Pentobarbital (Tyrell Biotechnology Co., Ltd., Shanghai, China). ChemiDoc touch imaging system (Bio-Rad Laboratories, Inc, USA)

\subsection{Experimental animals}

Male clean-grade, healthy C57BL/6J mice (Age: 20 month; body weight: 16 22 g) were used in the study. All the mice were provided by the Animal Experiment Center of Xinjiang Medical University. The Ethics Committee of the First Affiliated Hospital of Xinjiang Medical University approved this research. Transfect $5.0 \times 10^{11}$ virus genomes (VG) AAV9-HIF-1a (provided by out research group) were injected into mice through the tail vein to establish an isolated mice model of I/R injury. The flow chart was shown in Figure 1.

36 mice were randomly divided into 3 groups $(n=12)$ : 1) Blank (Sham) group: 180 min of perfusion; 2) Ischemiareperfusion (I/R) group: after $30 \mathrm{~min}$ of stable perfusion and $45 \mathrm{~min}$ of heart ischemia, $105 \mathrm{~min}$ of reperfusion was conducted; 3) I/R+2ME2 group (I/R+HIF-1 a blocker 2ME2): After $30 \mathrm{~min}$ of stable perfusion and $45 \mathrm{~min}$ of heart ischemia, $15 \mathrm{~min} 2 \mathrm{ME} 2$ plus 90 min reperfusion were conducted.

\subsection{Langendorff perfusion model establishment}

Aged C57BL/6J mice were intraperitoneally anesthetized and injected with $1 \%$ pentobarbital. We cut the anterior abdominal wall transversely under the costal margin in the supine position. Then, we cut the diaphragm along the abdomen's midline to the head, and the chest cavity was exposed along the midclavicular line on both sides. We separated the anterior mediastinum tissue, turn the anterior chest wall to the head, revealing the heart and the large blood vessels at the bottom of the heart, then quickly open the chest to remove the heart and separate the aorta. Then, We immediately put the heart into the pre-cooled $4{ }^{\circ} \mathrm{C} \mathrm{K}-\mathrm{H}$ solution to drain the blood in the heart cavity and take the No. 4 surgical wire to fix the heart on the Langendorff perfusion needle. A 1.4F Millar catheter was inserted from the heart's apex to the left ventricle and connected to the Powerlab/8SP pressure transducer system of the biological function to maintain the perfusion pressure $60-70 \mathrm{mmHg}$ and the left ventricular end diastolic pressure (LVEDP) at 0-10 mmHg (Shen et al., 2013).

\subsection{Isolated heart function monitoring}

The 1.4F Millar microcatheter and Powerlab multi-channel physiological recorder were used to monitor the hemodynamic changes during the whole process of in vitro perfusion in realtime. The Powerlab system was used to measure and record the left ventricular pressure changes at the end of equilibrium (T1) and reperfusion (T2). Heart rate (HR), left ventricular diastolic pressure (LVDP), LVEDP, maximal left ventricular pressure rising rate $(+\mathrm{dp} / \mathrm{dtmax})$ were then calculated.

\subsection{Myocardial infarction area measurement}

We immediately removed the heart and froze it in a refrigerator (temperature: $-80^{\circ} \mathrm{C}$ ) for $7 \mathrm{~min}$ at the end of reperfusion. After that, we sliced the heart from the apex to the bottom of the heart, and placed the slices n TTC solution (1\%, pH7.4) and incubated them at $37^{\circ} \mathrm{C}$ for $25 \mathrm{~min}$. Then We put the slices in $10 \%$ formaldehyde solution and fixed them overnight. The ImageJ software was conducted to analyze the infarct area by the pictures we took

\subsection{Western blot}

At the end of reperfusion, 6 mice were taken from each group, and the myocardium in the ischemia-risk area was cut out and stored in liquid nitrogen immediately. The total protein of myocardial tissue was extracted and lysed with tissue lysate. $30 \mu \mathrm{g}$ of the sample was taken, electrophoresed in an SDS-PAGE system, transferred to a membrane, and blocked at $37{ }^{\circ} \mathrm{C}$ for

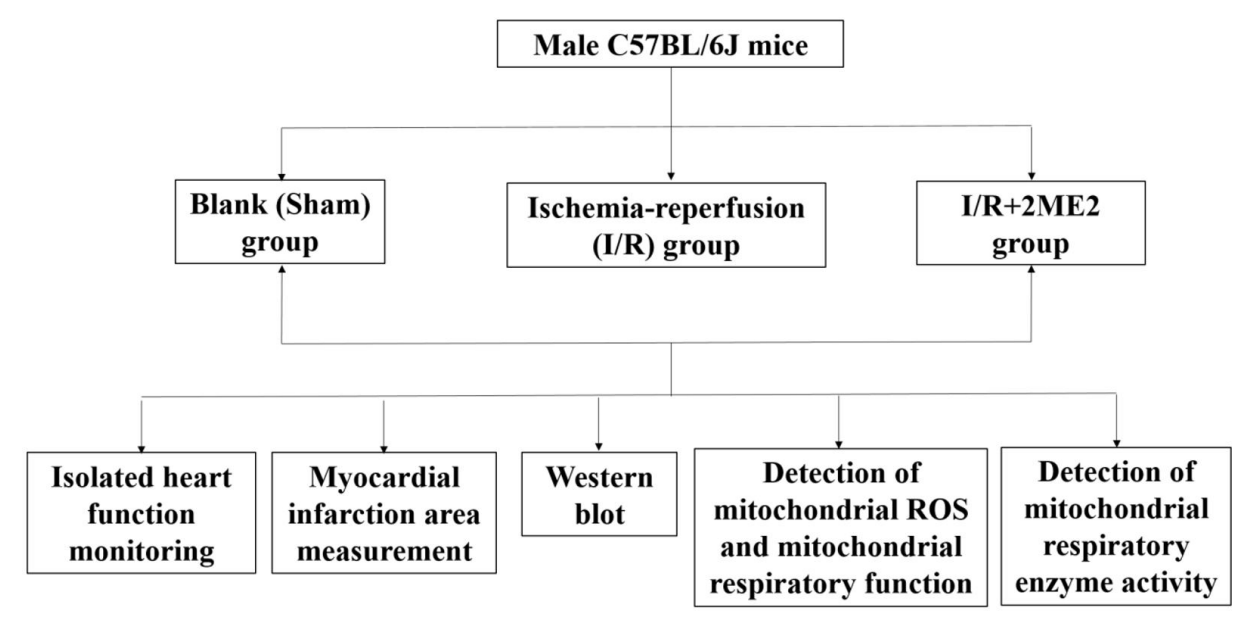

Figure 1. The flow chart. 
$2 \mathrm{~h}$. Then we added the 1:1000 primary HIF- $1 \alpha$ antibody and VEGF antibody to the sample and incubated it overnight $\left(4^{\circ} \mathrm{C}\right)$. After washing the membrane with TBST solution, the sample was incubated with HRP-labeled secondary antibody (1:5000) for $1 \mathrm{~h}$ at room temperature. After ECL color imaging, the Quantity One 2.6.2 image analysis system was used to analyze the target protein band's gray value.

\subsection{Detection of mitochondrial ROS and mitochondrial respiratory function}

After extracting myocardial mitochondria, the ROS kit was used to determine the mitochondrial ROS production rate (Roussel et al., 2000). The Bradford protein assay kit was used to quantify mitochondrial protein, and the sample protein concentration was calculated according to the standard curve. The mitochondrial respiratory function was measured $(3 \mathrm{~mL})$ with a Lufthansa oxygen electrode in a temperature-controlled oxygen cell equipped with magnetic stirring (Yang et al., 2020). We added $900 \mu \mathrm{L}$ of mitochondrial respiration assay medium to $37^{\circ} \mathrm{C} 1000 \mu \mathrm{L}$ reaction solution, equilibrating for $15 \mathrm{~min}$. Then we added $50 \mu \mathrm{L}$ of mitochondrial suspension (final quantitative concentration of protein $1 \mathrm{mg} / \mathrm{mL}$ ) and recorded the oxygen consumption curve for 20-30s. After the curve is stable, we added $10 \mu \mathrm{L}$ of succinic acid with a final concentration of $5 \mathrm{mmol} / \mathrm{L}$ and $1 \mu \mathrm{L}$ of rotenone with a final concentration of $2 \mu \mathrm{mol} / \mathrm{L}$, and record the curve for $1 \mathrm{~min}$, entering the state 4 respiration. Then we added $9 \mu \mathrm{L}$ of ADP with a final concentration of $100 \mu \mathrm{mol} / \mathrm{L}$ and recorded the oxygen consumption curve, entering the state 3 respiration. When ADP is completely phosphorylated and converted to ATP, the mitochondria enter the state 4 respiration. Mitochondrial respiratory control rate $(\mathrm{RCR})=$ state 3 respiratory oxygen consumption rate/ state 4 respiratory oxygen consumption rate.

\subsection{Detection of mitochondrial respiratory enzyme activity}

After the mitochondrial subunits (repeatedly freeze and thaw 3 times in the refrigerator at $20^{\circ} \mathrm{C}$ and $-80^{\circ} \mathrm{C}$ ) were prepared, the Clark oxygen electrode (Hansha science and technology group Co., Ltd., Hongkong) was used to complete the detection $(3 \mathrm{~mL})$ in a temperature-controlled oxygen cell equipped with magnetic stirring (Xiang et al., 2009). We added $900 \mu \mathrm{L}$ of cytochrome $\mathrm{C}$ oxidase assay medium, NADH oxidase assay medium, and succinate oxidase assay medium to $37^{\circ} \mathrm{C}$ $1000 \mu \mathrm{L}$ reaction solution, equilibrating for $15 \mathrm{~min}$, and added $50 \mu \mathrm{L}$ mitochondrial suspension (final protein concentration is $1 \mathrm{mg} / \mathrm{mL}$ ), then recorded the oxygen consumption curve for 5-10 $\mathrm{min}$.

\subsection{Statistical analysis}

Normal distributed data are revealed as mean \pm standard deviation (SD). Data were analyzed using SPSS v19.0 (SPSS Inc., Chicago, IL, USA). Univariate analysis was performed for comparison of variables among groups. ANOVA was performed for comparison of variables for intra-group. $P$ value less than 0.05 was considered statistically significant.

\section{Results}

\subsection{Hemodynamic changes}

Compared with the end of reperfusion, the cardiac function indexes of each group at the end of balance were better than those at the end of reperfusion $(\mathrm{P}<0.05)$; Compared with the Sham group, the HR, LVDP, and $+\mathrm{dp} / \mathrm{dtmax}$ in the I/R group and the $\mathrm{I} / \mathrm{R}+2 \mathrm{ME} 2$ group decreased $(\mathrm{P}<0.05)$, while the LVEDP in the $I / R$ group and the $I / R+2 M E 2$ group increased $(P<0.05)$ at the end of reperfusion; The levels of HR, LVDP, LVEDP and $+\mathrm{dp} / \mathrm{dtmax}$ in the I/R+2ME2 group were significantly lower than that in the $\mathrm{I} / \mathrm{R}$ group $(\mathrm{P}<0.05)($ Table 1$)$.

\subsection{Myocardial infarction area, $p$-HIF-1 $\alpha$ changes, $p$-VEGF changes, and mitochondrial ROS}

Compared with the Sham group, the area of myocardial infarction in the I/R group and the I/R+2ME2 group increased, and the ROS generation rate was significantly increased $(\mathrm{P}<0.05)$. Compared with the I/R group, the p-HIF- $1 \alpha$ and $p$-VEGF levels in the $\mathrm{I} / \mathrm{R}+2 \mathrm{ME} 2$ group decreased significantly $(\mathrm{P}<0.05)$ (Figure 2). The VEGF expression levels of $\mathrm{I} / \mathrm{R}+2 \mathrm{ME} 2$ group was lower than that of the Sham group and the I/R group (Figure 3 ). Application of HIF-1a blocker 2ME2 significantly eliminated the myocardial protective effect of AAV9-HIF-1a (Table 2).

\subsection{Mitochondrial respiratory function}

Compared with the Sham group, the mitochondrial respiratory function (state3, RCR) of the I/R group and the I/R+2ME2 group significantly decrease at the end of reperfusion $(\mathrm{P}<0.05)$; compared with the I/R group, the state 3 and RCR of I/R+2ME2 group reduced significantly $(\mathrm{P}<0.05)($ Table 3$)$.

\subsection{Respiratory enzyme activity of myocardial}

At the end of reperfusion, compared with the Sham group, the mitochondrial respiratory enzyme activities of the I/R group and $\mathrm{I} / \mathrm{R}+2 \mathrm{ME} 2$ group were significantly reduced $(\mathrm{P}<0.05)$. Blocker $2 \mathrm{ME} 2$ aggravated the decrease of mitochondrial respiratory enzyme activity $(\mathrm{P}<0.05)$ (Table 4$)$.

Table 1. Hemodynamic changes of isolated heart $(n=12)$.

\begin{tabular}{|c|c|c|c|c|c|c|c|c|}
\hline \multirow[b]{2}{*}{ Group } & \multicolumn{4}{|c|}{ T1 } & \multicolumn{4}{|c|}{$\mathrm{T} 2$} \\
\hline & $\begin{array}{c}\mathrm{HR} \\
\text { (beat/min) }\end{array}$ & $\begin{array}{c}\text { LVDP } \\
(\mathrm{mmHg})\end{array}$ & $\begin{array}{l}\text { LVEDP } \\
(\mathrm{mmHg})\end{array}$ & $\begin{array}{l}+\mathrm{dp} / \mathrm{dt}_{\text {max }} \\
(\mathrm{mmHg} / \mathrm{s})\end{array}$ & $\begin{array}{c}\mathrm{HR} \\
\text { (beat/min) }\end{array}$ & $\begin{array}{c}\text { LVDP } \\
(\mathrm{mmHg})\end{array}$ & $\begin{array}{c}\text { LVEDP } \\
(\mathrm{mmHg})\end{array}$ & $\begin{array}{l}+\mathrm{dp} / \mathrm{dt}_{\text {max }} \\
(\mathrm{mmHg} / \mathrm{s})\end{array}$ \\
\hline Sham & $362.00 \pm 11.31$ & $88.19 \pm 5.62$ & $2.24 \pm 0.87$ & $3132.43 \pm 204.24$ & $380.33 \pm 10.27^{\star}$ & $65.08 \pm 4.46^{*}$ & $9.75 \pm 1.16^{*}$ & $2377.86 \pm 216.64^{*}$ \\
\hline $\mathrm{I} / \mathrm{R}$ & $334.00 \pm 15.62$ & $91.83 \pm 5.61$ & $2.56 \pm 0.89$ & $3060.73 \pm 197.21$ & $359.83 \pm 9.54^{\star \&}$ & $56.70 \pm 4.71^{\star \&}$ & $11.93 \pm 1.24^{* \&}$ & $2118.88 \pm 190.80^{*} \&$ \\
\hline $\mathrm{I} / \mathrm{R}+2 \mathrm{ME} 2$ & $315.50 \pm 8.12$ & $90.12 \pm 6.03$ & $2.61 \pm 0.88$ & $3092.25 \pm 218.54$ & $337.50 \pm 6.50^{*} \& \$$ & $46.87 \pm 4.91^{* \& \$}$ & $16.46 \pm 1.37^{* \& \$}$ & $1665.19 \pm 206.16^{*} \& \$$ \\
\hline
\end{tabular}

Note: T1: At the end of equilibrium (stable perfusion for $30 \mathrm{~min}$ ); $\mathrm{T} 2$ : At the end of reperfusion. Compared with the T1 groups. ${ }^{\star} \mathrm{P}<0.05$, compared with the Sham group; ${ }^{\circledR} \mathrm{P}<0.05$, compared with the I/R group; ${ }^{\$} \mathrm{P}<0.05$. 


\section{Discussion}

In this study, referring to the literature (Xiang et al., 2009), we used the NCBI database to retrieve the mouse HIF-1 $\alpha$ gene sequence, constructed the recombinant shuttle plasmid pFB-AAV-

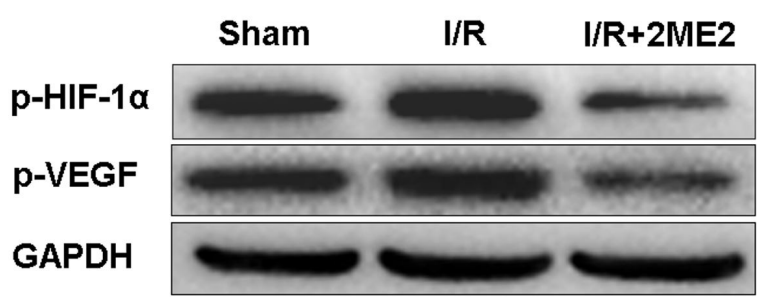

Figure 2. Protein expression of p-HIF-1a, p-VEGF, and GAPDH

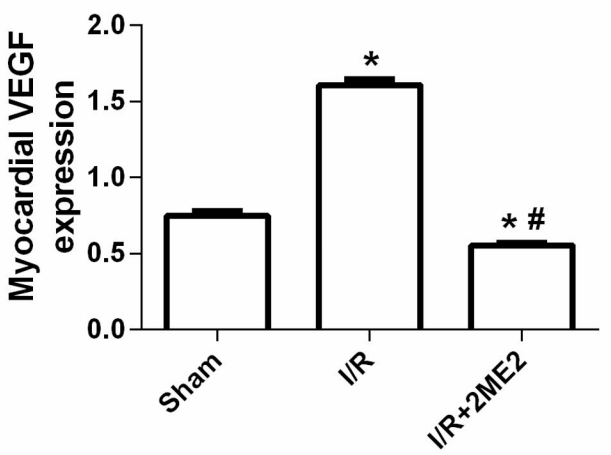

Figure 3. Protein expression of myocardial VEGF. ${ }^{\star} \mathrm{p}<0.05$, versus the sham group; $\# \mathrm{p}<0.05$, versus the I/R group.
CMV-HIF-1 $\alpha$, transformed the DH10Bac bacteria, extracted the recombinant Bacmid-AAV-CMV-HIF-1 $\alpha$ DNA, and packaged it into Recombinant viral vector AAV9-HIF-1 $\alpha$. Purification was performed by cesium chloride density gradient centrifugation. Fluorescence quantitative PCR was used to determine the titer of the recombinant virus. The virus's morphology was observed by scanning electron microscope, and the purity of the virus was identified by SDS-PAGE gel electrophoresis (Chen et al., 2017). The expression of HIF-1 1 increases in ischemia-hypoxic myocardial injury and plays an important role in myocardial protection. HIF-1a up-regulates vascular endothelial growth factor. Increased expression of vascular endothelial growth factor can advance angiogenesis, increase blood perfusion and oxygen supply in ischemic tissues, and promote microcirculation reconstruction after myocardial ischemia. HIF-1a improves energy metabolism disorder after myocardial hypoxia (Wei et al., 2012). When myocardial ischemia occurs, the process of oxidative phosphorylation is inhibited, and the expression of HIF-1a increases. It regulates myocardial energy metabolism through glycolysis and protects heart function. The activation of HIF-1a can improve the tolerance of cardiomyocytes to ischemia and hypoxia, reducing the apoptosis of cardiomyocytes (Belaidi et al., 2008). After $5.0 \times 10^{11}$ VG AAV9-HIF-1 $a$ was injected into the tail vein, myocardial infarction area and the ROS in the I/R group and the I/R+2ME2 group increased compared with the Shan group, confirming the myocardial transfection of AAV9- HIF$1 \alpha$ is directly related to the reduction of myocardial I/R injury in isolated aged mice.

The time point and dose of HIF-1a blocker 2ME2 were selected according to the research (Wu et al., 2017). During

Table 2. Comparison of myocardial infarction area, p-HIF-1 $\alpha$ changes, $p$-VEGF changes and mitochondrial ROS detection among three groups $(\mathrm{n}=12)$.

\begin{tabular}{ccccc}
\hline Group & $\begin{array}{c}\text { myocardial infarction area } \\
(\%)\end{array}$ & $\begin{array}{c}\text { mitochondrial ROS } \\
\left(\text { u.s.-1. } \text { m }^{-1}\right)\end{array}$ & p-HIF-1a & p-VEGF \\
\hline Sham & $6.34 \pm 1.67$ & $6.67 \pm 1.01$ & $0.72 \pm 0.10$ & $0.75 \pm 0.08$ \\
I/R & $37.24 \pm 23.9^{\&}$ & $12.60 \pm 1.96^{\&}$ & $1.45 \pm 0.13^{\&}$ & $1.61 \pm 0.09^{\&}$ \\
I/R+2ME2 & $52.82 \pm 5.67^{\& \&}$ & $20.38 \pm 1.66^{\& \&}$ & $0.50 \pm 0.07^{\& \&}$ & $0.55 \pm 0.04^{\& \&}$ \\
\hline
\end{tabular}

Note: Compared to the Sham group. ${ }^{*} \mathrm{P}<0.05$, compare to the I/R group; ${ }^{\text {P }}<0.05$.

Table 3. Mitochondrial respiratory function changes $(\mathrm{n}=12)$.

\begin{tabular}{|c|c|c|c|c|}
\hline \multirow{2}{*}{ Group } & \multicolumn{2}{|c|}{$\mathrm{T} 1$} & \multicolumn{2}{|c|}{$\mathrm{T} 2$} \\
\hline & State3 (nmol/min·mg.pro) & RCR & State3 (nmol/min·mg.pro) & RCR \\
\hline Sham & $120.95 \pm 4.98$ & $2.10 \pm 0.09$ & $91.50 \pm 5.40^{*}$ & $1.83 \pm 0.09^{*}$ \\
\hline $\mathrm{I} / \mathrm{R}$ & $117.14 \pm 4.68$ & $2.04 \pm 0.10$ & $76.13 \pm 5.11^{* \&}$ & $1.50 \pm 0.07^{*} \&$ \\
\hline $\mathrm{I} / \mathrm{R}+2 \mathrm{ME} 2$ & $120.70 \pm 4.95$ & $2.05 \pm 0.08$ & $60.82 \pm 4.11^{\star 2 \$}$ & $1.05 \pm 0.06^{* \& \$}$ \\
\hline
\end{tabular}

Note: T1: At the end of equilibrium (stable perfusion for $30 \mathrm{~min}$ ); $\mathrm{T} 2$ : At the end of reperfusion. Compared to the $\mathrm{T} 1$ groups. ${ }^{\star} \mathrm{P}<0.05$, compared to the Sham group; ${ }^{\circledR} \mathrm{P}<0.05$, compared to the I/R group; ${ }^{\$} \mathrm{P}<0.05$.

Table 4. Comparison of respiratory enzyme activity of mitochondrial $(\mathrm{n}=12)(\mathrm{nmol} / \mathrm{min} \cdot \mathrm{mg} \cdot \mathrm{pro})$.

\begin{tabular}{|c|c|c|c|c|c|c|}
\hline \multirow{2}{*}{ Group } & \multicolumn{3}{|c|}{ T1 } & \multicolumn{3}{|c|}{$\mathrm{T} 2$} \\
\hline & NADH-OX & Cytc-OX & SUC-OX & NADH-OX & Cytc-OX & SUC-OX \\
\hline Sham & $218.21 \pm 10.81$ & $62.72 \pm 6.61$ & $75.04 \pm 6.70$ & $151.74 \pm 8.69^{*}$ & $52.85 \pm 5.87^{\star}$ & $59.55 \pm 5.84^{*}$ \\
\hline $\mathrm{I} / \mathrm{R}$ & $220.49 \pm 10.48$ & $66.08 \pm 6.62$ & $77.82 \pm 8.13$ & $137.95 \pm 7.68^{* \&}$ & $42.24 \pm 6.90^{* 8}$ & $46.89 \pm 6.56^{* \&}$ \\
\hline $\mathrm{I} / \mathrm{R}+2 \mathrm{ME} 2$ & $220.10 \pm 8.69$ & $66.27 \pm 5.45$ & $74.35 \pm 5.75$ & $120.96 \pm 8.84^{\star \& \$}$ & $26.57 \pm 5.02^{* \& S}$ & $37.64 \pm 4.68^{* \& \$}$ \\
\hline
\end{tabular}

Note: T1: At the end of equilibrium (stable perfusion for $30 \mathrm{~min}$ ); T2: At the end of reperfusion. Compared with the T1 groups. ${ }^{\star} \mathrm{P}<0.05$, compared to the Sham group; ${ }^{\circledR} \mathrm{P}<0.05$, compared to the I/R group; ${ }^{\$} \mathrm{P}<0.05$. 
myocardial ischemia, up-regulation of HIF- $1 \alpha$ mediates a variety of downstream hypoxia-sensitive genes to play a myocardial protective effect, improving myocardial tolerance to acute ischemia reperfusion injury (Xie et al.,2017). The results of this study indicated that at the end of reperfusion, the levels of p-HIF- $1 \alpha$ and $p$-VEGF in the I/R group increased compared with the Sham group, which is related to the active up-regulation of HIF- $1 a$ levels after myocardial ischemia and hypoxia. However, the application of HIF-1 $\alpha$ blocker 2ME2 significantly eliminated the regulation of HIF-1 $\alpha$ and downstream VEGF proteins caused by transfection of AAV9-HIF-1 $\alpha$ and increased the risk of myocardial I/R injury.

According to the literature (Yang et al., 2020), the Bradford protein assay kit was used to measure the function of mitochondrial respiratory. Mitochondrial respiratory function (State 3 and RCR) is a crucial indicator for evaluating mitochondrial function (Yang et al., 2019). The results of this study demonstrated that, at the end of reperfusion, the state 3 and RCR of myocardial mitochondria in the I/R group and I/R+2ME2 group were significantly decreased. The HIF-1 $\alpha$ blocker 2 ME2 significantly weakened the myocardial mitochondria's respiratory function in the aged mice, showing that the up-regulation of HIF-1a protein level is an essential means to protect mitochondrial respiratory function.

Mitochondrial respiratory function and enzyme activity can directly or indirectly reflect mitochondrial structure and function (Wang et al., 2020; Zhang et al., 2018). This study detected mitochondrial respiratory enzyme activity at the end of equilibrium (stable perfusion for $30 \mathrm{~min}$ ) and the end of reperfusion. It was found that the ischemic injury and the application of HIF-1a blocker 2ME2 significantly reduced the respiratory enzyme activity of myocardial, indicating that the application of HIF- $1 \alpha$ blocker $2 \mathrm{ME} 2$ is effective. It is confirmed that the level of HIF-1 $a$ protein is directly related to mitochondrial respiratory enzymes' activity.

In summary, when myocardial I/R injury occurs in aged mice, myocardial Transfection with AAV9-HIF-1a reduces the area of myocardial infarction, reduces the rate of ROS production, and increases the level of HIF-1 1 p protein to promote the production of downstream hypoxia sensitive gene VEGF. At the same time, myocardial transfection with AAV9-HIF-1a enhance the respiratory enzyme activity of myocardial and respiratory function of myocardial mtochondrial. However, the application of HIF-1 $a$ blocker 2ME2 significantly abolished the myocardial protection produced by AAV9-HIF-1 $\alpha$. It is confirmed that the HIF-1 a pathway upregulate the respiratory enzyme activity of myocardial and respiratory function of myocardial mtochondrial.

\section{Conflict of interest}

None

\section{Funding}

Key Laboratory Open Project of Xinjiang Uygur Autonomous Region(2017D04007)

\section{Author contributions}

guarantor of integrity of the entire study: Jiang Wang

study concepts: Tiantian Zou

study design: Jiang Wang

definition of intellectual content: Jianjiang $\mathrm{Wu}$

literature research: Tailaiti-Taiwangu

experimental studies: Long Yang

data acquisition: Siyu Chen

data analysis: Siyu Chen

statistical analysis: Tailaiti.Taiwangu

manuscript preparation: Jianjiang $\mathrm{Wu}$

manuscript editing: Tiantian Zou

manuscript review: Tiantian Zou

\section{References}

Andersen, A., Agerlund Povlsen, J., Bøtker, H. E., \& Nielsen-Kudsk, J. E. (2012). Ischemic preconditioning reduces right ventricular infarct size through opening of mitochondrial potassium channels. Cardiology, 123(3), 177-180. http://dx.doi.org/10.1159/000342481. PMid:23128893.

Belaidi, E., Beguin, P. C., Levy, P., Ribuot, C., \& Godin-Ribuot, D. (2008). Prevention of HIF-1 activation and iNOS gene targeting by low-dose cadmium results in loss of myocardial hypoxic preconditioning in the rat. American Journal of Physiology. Heart and Circulatory Physiology, 294(2), H901-H908. http://dx.doi.org/10.1152/ajpheart.00715.2007. PMid:18083903.

Bratic, A., \& Larsson, N. G. (2013). The role of mitochondria in aging. The Journal of Clinical Investigation, 123(3), 951-957. http://dx.doi. org/10.1172/JCI64125. PMid:23454757.

Chen, Q., Zhai, H., Li, X., Ma, Y., Chen, B., Liu, F., Lai, H., Xie, J., He, C., Luo, J., Gao, J., \& Yang, Y. (2017). Recombinant adeno-associated virus serotype 9 in a mouse model of atherosclerosis: Determination of the optimal expression time in vivo. Molecular Medicine Reports, 15(4), 2090-2096. http://dx.doi.org/10.3892/mmr.2017.6235. PMid:28260093.

Coswosck, K., Giorgette, M. A., Lepaus, B. M., Silva, E. M. M., Sena, G. G. S., Azevedo, M. C. A., \& São José, J. F. B. (2021). Impact of alternative sanitizers on the physicochemical quality, chlorophyll content and bioactive compounds of fresh vegetables. Food Science and Technology (Campinas), 41(2), 328-334. http://dx.doi.org/10.1590/ fst.02320.

Cruz-Ramírez, S.-G., López-Saiz, C.-M., Rosas-Burgos, E.-C., CincoMoroyoqui, F.-J., Velázquez, C., Hernández, J., \& Burgos-Hernández, A. (2021). Antimutagenic bis (2-ethylhexyl) phthalate isolated from octopus (Paraoctopus vulgaris). Food Science and Technology (Campinas), 41(2), 314-320. http://dx.doi.org/10.1590/fst.26119.

Gupta, P. K., Gupta, H., Sundaram, A., Kaushik, M., Fang, X., Miller, W. J., Esterbrooks, D. J., Hunter, C. B., Pipinos, I. I., Johanning, J. M., Lynch, T. G., Forse, R. A., Mohiuddin, S. M., \& Mooss, A. N. (2011). Development and validation of a risk calculator for prediction of cardiac risk after surgery. Circulation, 124(4), 381-387. http://dx.doi. org/10.1161/CIRCULATIONAHA.110.015701. PMid:21730309. 
Jain, T., Nikolopoulou, E. A., Xu, Q., \& Qu, A. (2018). Hypoxia inducible factor as a therapeutic target for atherosclerosis. Pharmacology \& Therapeutics, 183, 22-33. http://dx.doi.org/10.1016/j. pharmthera.2017.09.003. PMid:28942242.

Ong, S. G., Lee, W. H., Theodorou, L., Kodo, K., Lim, S. Y., Shukla, D. H., Briston, T., Kiriakidis, S., Ashcroft, M., Davidson, S. M., Maxwell, P. H., Yellon, D. M., \& Hausenloy, D. J. (2014). HIF-1 reduces ischaemia-reperfusion injury in the heart by targeting the mitochondrial permeability transition pore. Cardiovascular Research, 104(1), 24-36. http://dx.doi.org/10.1093/cvr/cvu172. PMid:25063991.

Roussel, D., Lhenry, F., Ecochard, L., Sempore, B., Rouanet, J. L., \& Favier, R. (2000). Differential effects of endurance training and creatine depletion on regional mitochondrial adaptations in rat skeletal muscle. The Biochemical Journal, 350(Pt 2), 547-553. http:// dx.doi.org/10.1042/bj3500547. PMid:10947970.

Shen X, Ma YT, Yang YN, Liu F, Yu ZX, Chen BD, Chen Y, Huang Y. (2013). Effects of different ages on ventricular remodeling after ischemic heart failure in mice. Chinese Journal of Pathophysiology, 29(6):988-992. http://dx.doi.org/10.3969/j.issn.1000-4718.2013.06.005.

Tekin, D., Dursun, A. D., \& Xi, L. (2010). Hypoxia inducible factor 1 (HIF-1) and cardioprotection. Acta Pharmacologica Sinica, 31(9), 1085-1094. http://dx.doi.org/10.1038/aps.2010.132. PMid:20711226.

Wang, L. Y., Cheng, X. X., \& Xu, Z. L. (2020). Regulatory effect of the zinc transporter Zip2 on cardiomyocyte mitochondrial respiration function after cardiac ischemia-reperfusion injury in mice. Sheng Li Xue Bao : [Acta Physiologica Sinica], 72(4), 433-440. [Chinese]. http://dx.doi.org/10.13294/j.aps.2020.0041. PMid:32820305.

Wei, H., Bedja, D., Koitabashi, N., Xing, D., Chen, J., Fox-Talbot, K., Rouf, R., Chen, S., Steenbergen, C., Harmon, J. W., Dietz, H. C., Gabrielson, K. L., Kass, D. A., \& Semenza, G. L. (2012). Endothelial expression of hypoxia-inducible factor 1 protects the murine heart and aorta from pressure overload by suppression of TGF- $\beta$ signaling. Proceedings of the National Academy of Sciences of the United States of America, 109(14), E841-E850. http://dx.doi.org/10.1073/ pnas.1202081109. PMid:22403061.

Williams, A. L., Walton, C. B., MacCannell, K. A., Avelar, A., \& Shohet, R. V. (2019). HIF-1 regulation of miR-29c impairs SERCA2 expression and cardiac contractility. American Journal of Physiology. Heart and Circulatory Physiology, 316(3), H554-H565. http://dx.doi.org/10.1152/ ajpheart.00617.2018. PMid:30575439.

Wu, J., Yang, L., Xie, P., Yu, J., Yu, T., Wang, H., Maimaitili, Y., Wang, J., Ma, H., Yang, Y., \& Zheng, H. (2017). Cobalt chloride upregulates impaired HIF-1 alpha expression to restore sevoflurane postconditioning-dependent myocardial protection in diabetic rats. Frontiers in Physiology, 8, 395. http://dx.doi.org/10.3389/ fphys.2017.00395. PMid:28659817.
Xiang, Y., Ma, Y. T., Yang, Y. N., Chen, B. D., Liu, F., \& Gao, X. (2009). Transfection of recombinant adeno-associated virus serotype 9 to mouse heart in vivo and the impact on cardiac function. Chinese Journal of Microbiology and Immunology, (10), 899-902.

Xie, P., Yang, L., Talaiti, A., Wu, J. J., Yu, J., Yu, T., Wang, H. Y., Huang, B., Wu, Q., Maimaitili, Y., Wang, J., Ma, H. P., Yang, Y. N., \& Zheng, H. (2017). Deferoxamine-activated hypoxia-inducible factor-1 restores cardioprotective effects of sevoflurane postconditioning in diabetic rats. Acta Physiologica (Oxford, England), 221(2), 98-114. http://dx.doi.org/10.1111/apha.12874. PMid:28316125.

Yan, W., Jiang, L., \& Xu, J. (2020). Cyclocarya paliurus (Batal.) Iljinskaja polysaccharides alleviate type 2 diabetes mellitus in rats by resisting inflammatory response and oxidative stress. Food Science and Technology (Campinas), 40(suppl. 1), 158-162. http://dx.doi. org/10.1590/fst.06619.

Yang, L., Wu, J., Xie, P., Yu, J., Li, X., Wang, J., \& Zheng, H. (2019). Sevoflurane postconditioning alleviates hypoxia-reoxygenation injury of cardiomyocytes by promoting mitochondrial autophagy through the HIF-1/BNIP3 signaling pathway. Peer J, 7, e7165. http:// dx.doi.org/10.7717/peerj.7165.

Yang, L., Xie, P., Wu, J., Yu, J., Li, X., Ma, H., Yu, T., Wang, H., Ye, J., Wang, J., \& Zheng, H. (2020). Deferoxamine treatment combined with sevoflurane postconditioning attenuates myocardial ischemiareperfusion injury by restoring HIF-1/BNIP3-mediated mitochondrial autophagy in GK rats. Frontiers in Pharmacology, 11, 6. http://dx.doi. org/10.3389/fphar.2020.00006. PMid:32140105.

Zhang, X., Xiao, Z., Yao, J., Zhao, G., Fa, X., \& Niu, J. (2013). Participation of protein kinase $\mathrm{C}$ in the activation of $\mathrm{Nrf} 2$ signaling by ischemic preconditioning in the isolated rabbit heart. Molecular and Cellular Biochemistry, 372(1-2), 169-179. http://dx.doi.org/10.1007/s11010012-1458-9. PMid:23010891.

Zhang, G., Sheng, M., Wang, J., Teng, T., Sun, Y., Yang, Q., \& Xu, Z. (2018). Zinc improves mitochondrial respiratory function and prevents mitochondrial ROS generation at reperfusion by phosphorylating STAT3 at Ser727. Journal of Molecular and Cellular Cardiology, 118, 169-182. http://dx.doi.org/10.1016/j.yjmcc.2018.03.019. PMid:29605530.

Zhao, Z. Q., \& Vinten-Johansen, J. (2006). Postconditioning: reduction of reperfusion-induced injury. Cardiovascular Research, 70(2), 200-211. http://dx.doi.org/10.1016/j.cardiores.2006.01.024. PMid:16545349.

Zhu, B. L., Tanaka, S., Ishikawa, T., Zhao, D., Li, D. R., Michiue, T., Quan, L., \& Maeda, H. (2008). Forensic pathological investigation of myocardial hypoxia-inducible factor-1 alpha, erythropoietin and vascular endothelial growth factor in cardiac death. Legal medicine (Tokyo, Japan), 10(1), 11-19. http://dx.doi.org/10.1016/j. legalmed.2007.06.002. PMid:17698391. 